\title{
Residencia: Proyecto MUTE, estética del exceso y discurso oculto
}

\author{
Angie Saiz, artista visual \\ angiesaiz@gmail.com / http://www.angiesaiz.com
}

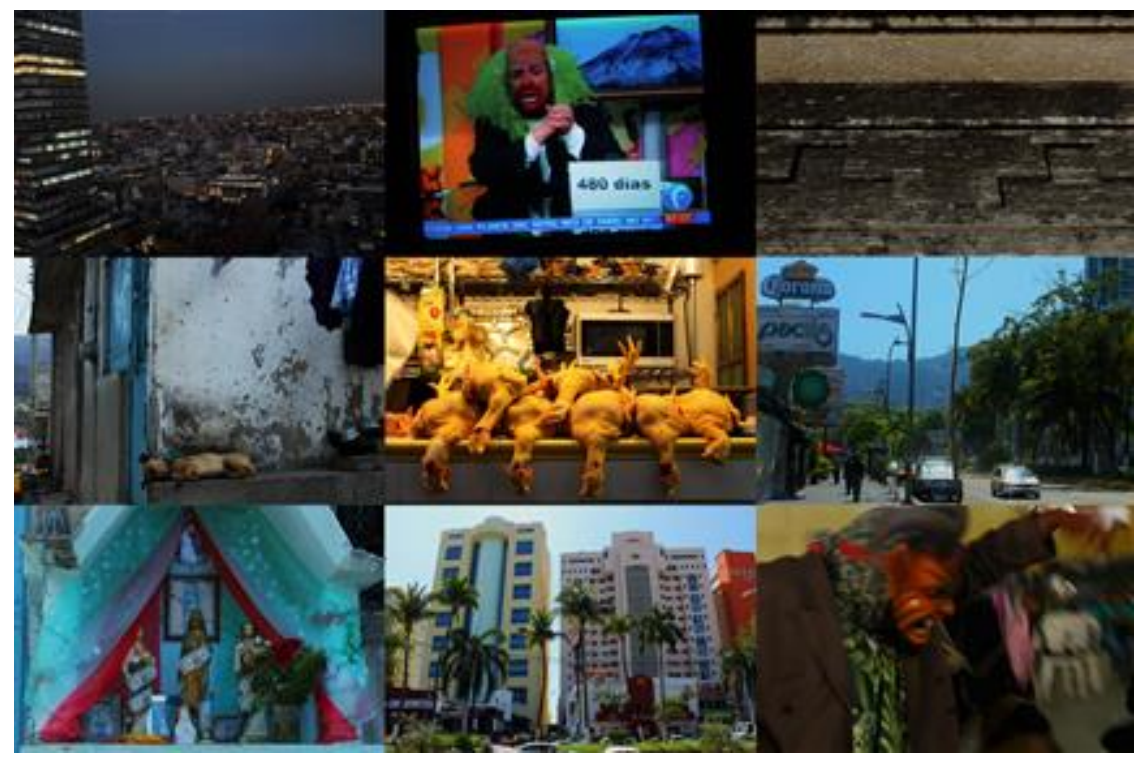

1. Imágenes del recorrido de investigación del proyecto MUTE en México. Ciudad de México, Puebla, Cholula, Acapulco, Tlapa, Zacatecas, Real de 14, Querétaro, Cuernavaca y Mérida.

Dejar el lugar propio permite. En la zona propia (u otra apropiada) se suele construir el acomodo necesario para sobrellevar el pequeño mundo que se repite. Repite. Repite. Repite. Espacios, socios, comportamientos, estrategias emotivas, pares, fórmulas, obras, intercambios, etc, etc, etc.

El viaje y residencia, aun cuando móvil, permite ver que esa zona de resguardo existe solo cuando hay un medio del cual protegerse. Fuera de él, ésta desaparece. Se abre información, contactos, posibilidades, gustos, apreciaciones, prejuicios y más; cambian los bordes, las perspectivas, los discursos, las importancias, la comprensión. La zona se entremezcla de pronto con el tomar-dejar, perturbando con el tiempo y la experiencia cierta absurda hegemonía cotidiana autoimpuesta. La zona se disuelve, volviéndose cada vez más imperceptible y leve, hasta que ya no se siente, no se escucha, ni se respira en ella.

$$
\text { ¿Dónde estoy? Afuera. }
$$


Angie Saiz. Residencia: Proyecto MUTE, estética del exceso y discurso oculto.

\section{Sobre MUTE}

\section{por Victoria Narro, Círculo A}

En enero de 2016, Angie Saiz presentó Mute, proyecto en desarrollo que se gestó en Chile especialmente para su residencia en [RAT] Residencias Artísticas por Intercambio, México, y que reúne obra en distintos medios audiovisuales como video, fotografía y collage, entre otros. De este proyecto ya se han desprendido dos exposiciones, Más Power (Acapulco, febrero de 2016) y Milicia Ficción (Zacatecas, marzo de 2016).

Mute es la continuación del trabajo que comenzó con la muestra Flesh World (Galería Panam, Santiago, julio de 2015), donde Saiz explora la memoria chilena bajo la óptica del postrauma producido por los años de dictadura. Saiz describe esta nueva serie a partir de la definición del término mute como un momento en el que la imagen reproducida en un aparato puede verse, pero no escucharse. Esa falta de audio podría pensarse como una ausencia, pero en realidad intenta descubrir la presencia de algo que se enmascara tras los discursos.

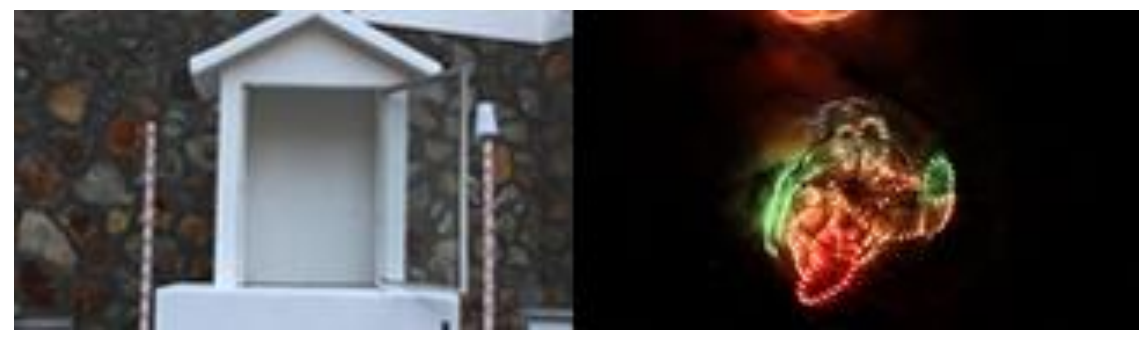

2. Frames video Más Power, disponible en: https://vimeo.com/156125698.

Un excelente ejemplo para entender esta serie es el video presentado en Acapulco que lleva el título de la muestra, Más Power, grabado con una cámara fija, registro color, y por supuesto, sin sonido. En él vemos que un hombre arregla un pequeño altar de la Virgen de Guadalupe (son altares públicos, como pequeñas casitas con puertas de vidrio que resguardan una figura; aquí en México están en los comercios, los parques, las calles, las tiendas y las casas; Angie dice que las vírgenes más bonitas las ha visto en los estacionamientos públicos). Después de un tiempo, que parece alargarse, a este hombre se une otro que supervisa y reacomoda un poco los floreros, la veladora y también la figura de la Virgen. Ambos encienden la vela para finalmente cerrar el altar e irse. La imagen se cierra sobre la vela que está dentro de un vaso rojo y poco a poco la imagen del plástico rojo va quedando de lado para dar paso a un juego de fuegos artificiales de colores, que acá llamamos cohetes. 


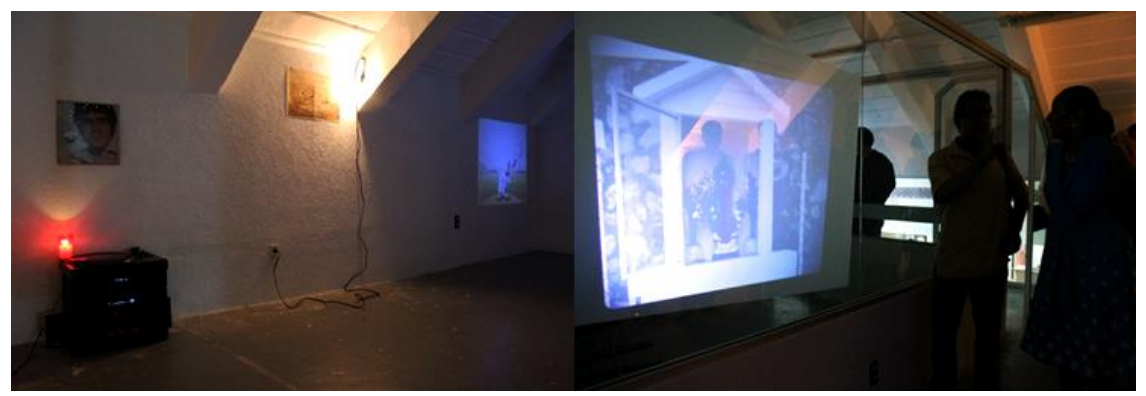

3. Registro exposición Más Power, Acapulco, 2016.

Como es fácil de imaginar en este video, la imagen predomina. Saiz no tiene que insistir en que hay que concentrarse en la acción y su ritmo, en cada una de las escenas, sobre cualquier ruido ambiental, sobre cualquier diálogo, sobre cualquier partitura, está la imagen.

¿Quiénes son esos hombres?, ¿qué importancia tiene un altar?, ¿por qué esta historia no me da imágenes de lugares y de gente hermosa, sino de vasos plásticos y ferias con cohetes que no son nítidos ni de alto contraste? Y no, no me hacen desear estar allí. Lentamente se hace evidente la distancia de estas imágenes y las de carácter mediático, las de anuncios de televisión, las de las series hechas en Estados Unidos, las de los videos de música, las imágenes que tienen un acabado brillante, con puestas de sol, muebles bonitos, gente bella. Saiz afirma que existe una estética del trauma en toda América Latina, en realidad en todo el tercer mundo; los colonizados tenemos una multitud de discursos y deseos internos que se contradicen unos con otros. Tenemos muchas veces ideas biopolíticas radicales, que pugnan íntimamente con el deseo de tener un coche con asientos de piel, por ejemplo. Los medios con toda su publicidad alimentan nuestros deseos y nos ayudan a evadirnos.

Ya con esta simple observación podemos decir que en el trabajo de Saiz hay una preocupación política que tiene que ver con los modelos económicos del neoliberalismo y su funcionamiento opresivo, oprobioso, que lo principal es la afirmación en el uso de la imagen popular (de pueblo), pero sin ser lo suyo lo existencialista o lo poético. No problematiza la "idea de identidad" de acuerdo al programa artístico general, sino que la imagen es un reto, es una cita a lo cotidiano, a lo común, a lo corriente, a lo popular, a lo que existe en el registro de lo inculto. El gesto de los hombres de Más Power no es un acto del artista dirigido a la conciencia burguesa de su observador, sino más bien es la reproducción y captura casi antropológica de un rito extendido y centenario, una persistente resistencia cultural. 
Angie Saiz. Residencia: Proyecto MUTE, estética del exceso y discurso oculto.

En los textos que escribe Saiz para presentar sus proyectos y en la conferencia que diera en la montaña de Tlapa, Guerrero, a un público mayoritariamente rural e indígena, subraya la importancia de lo cotidiano, de lo que omitimos en nuestros análisis, en nuestros textos, en nuestra vida para dar sentido a lo que hacemos, y es justamente esto lo que revela nuestra ideología, nuestra posición en el mundo, la forma en la que vivimos:

La resistencia existe, está presente en pequeños indicios dentro de la cadena impuesta por medio del lenguaje y lo que se expresa, esa disidencia vive en la convicción de que el miedo al poder es de alguna forma menor al miedo a perder el propio poder; ese motor que con discursos ocultos critica a un sistema de masas que omite las tradiciones y cultura identitaria constructoras del pertenecer. Fiestas tradicionales, lengua indígena, carnavales, gastronomía prehispánica, costumbres locales, oficios no mercantilizados, sistemas de economía comunitaria, una eterna lista de resistencia (Texto completo en http://www.circuoa.com/discurso-oculto-y-travestismo-cliche/).

La estética del trauma. La identidad no puede ser y no debe ser institucionalizada, y esa es la cuestión central de Más Power. La imagen no se impone como un extraño para crear un deseo. Las imágenes revelan la pertenencia del sujeto y del objeto. Las prácticas identitarias son la forma más radical de resistencia.

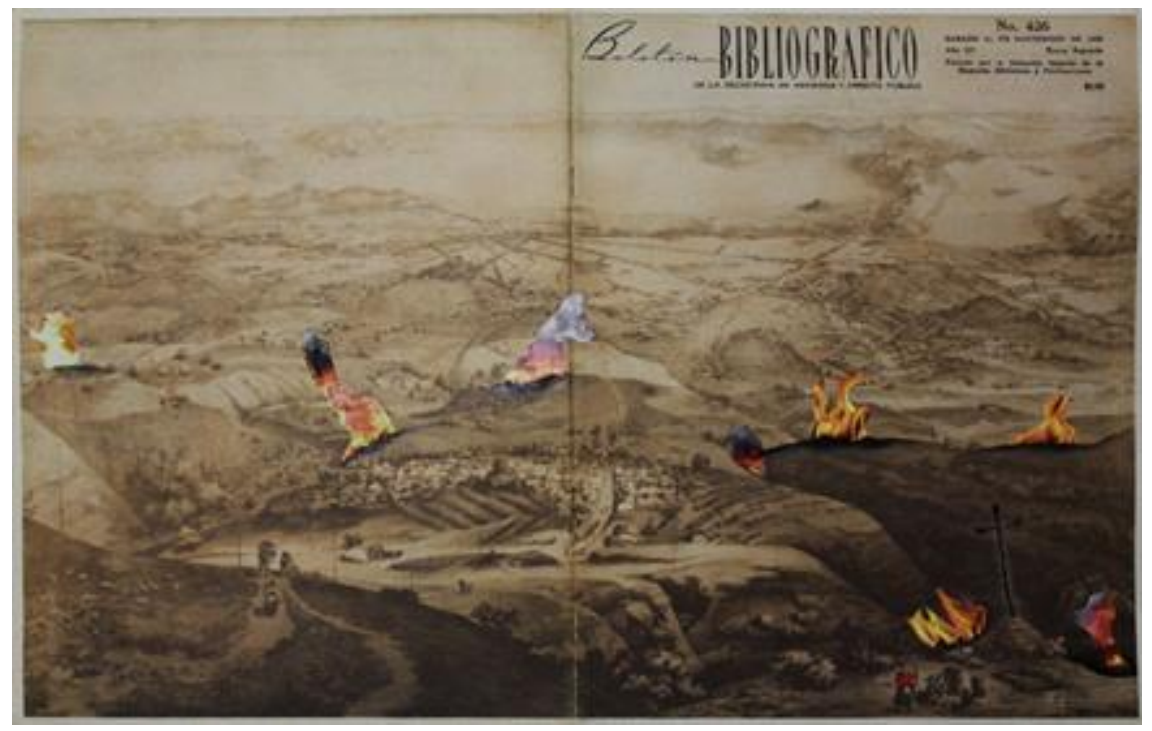

4. Collage parte del conjunto de muestra Más Power 


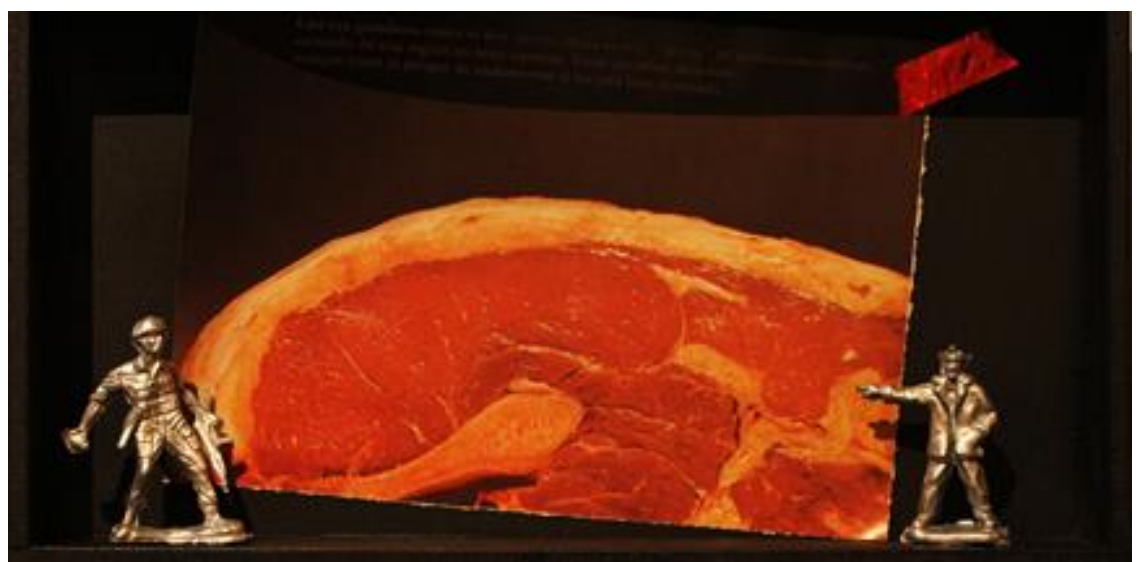

A los grupos que carecen de poder les interesa, mientras no recurren a una verdadera rebelión, conspirar para reforzar las apariencias hegemónicas. Cuanto más amenazante sea el poder, más gruesa será la máscara. James C. Scott
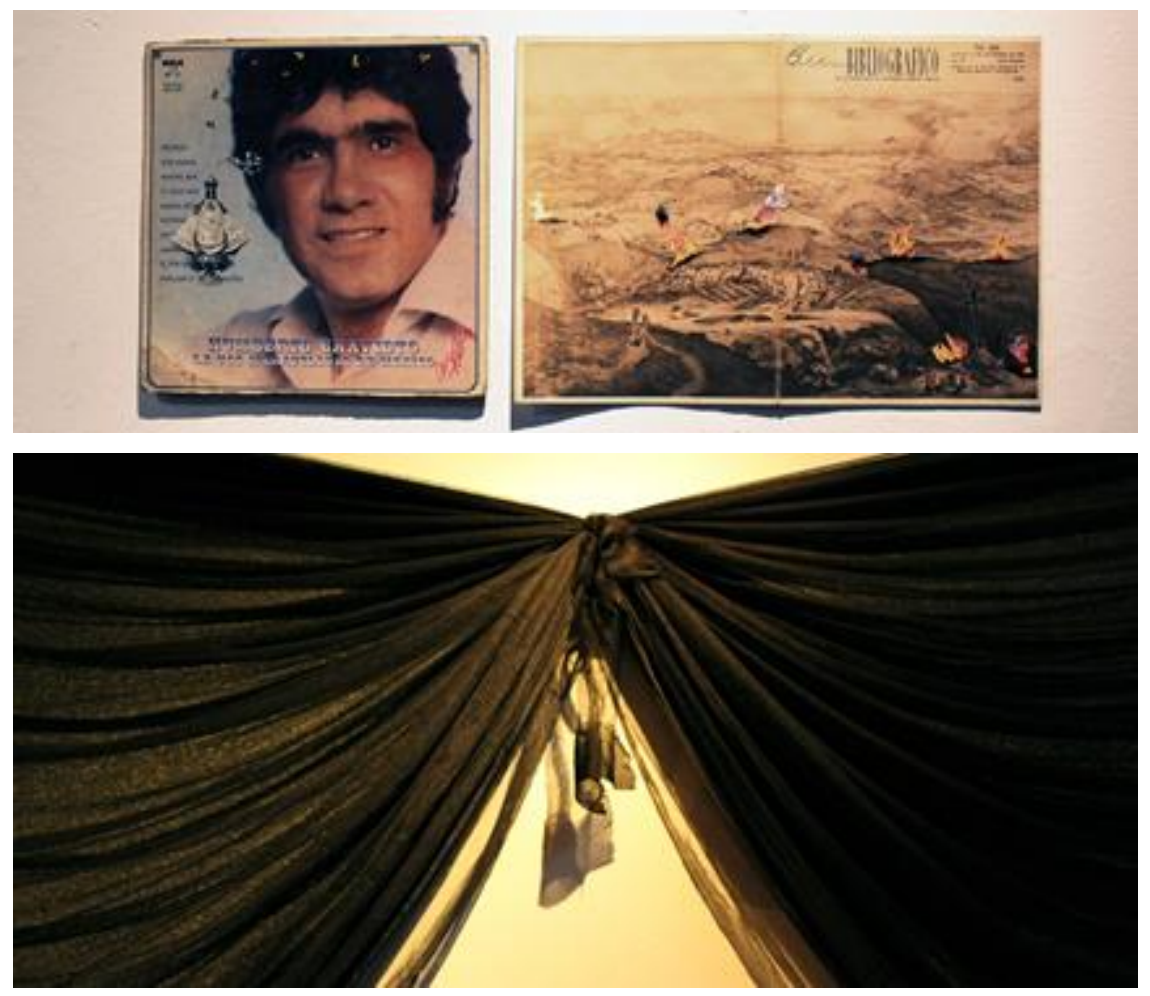

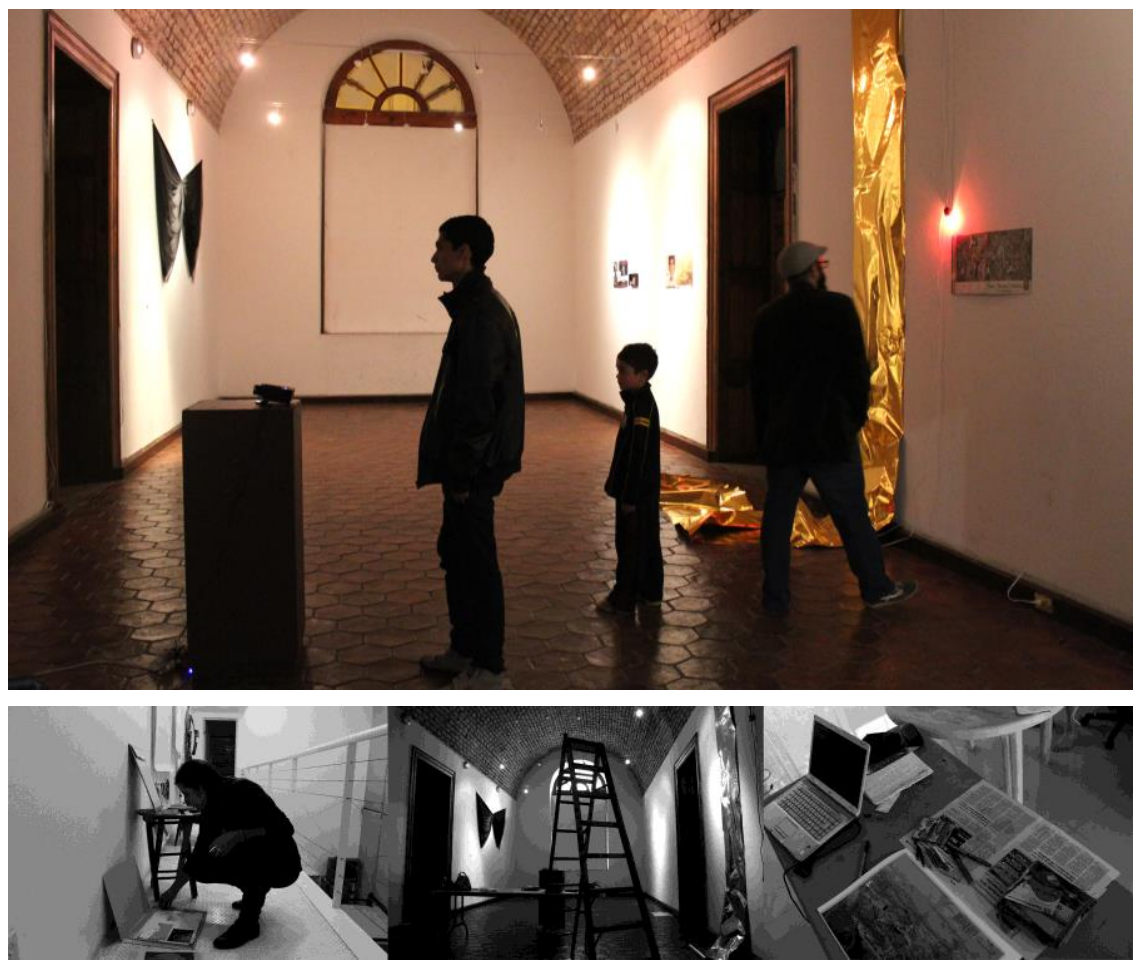

Gracias MUTE: Carolina Saiz, Danna Levín y Sergio González, [RAT] Puerto Mitla, Puerto Turín, Puerto Acapulco, Alondra Berber y Luis Ayala, Sergio Ferrer, Victoria Narro, Fernanda Mejías y Miguel Rodríguez, Circulo A (circuloa.com), Revista Escaner Cultural (revista.escaner.cl), Casa de la Cultura de Acapulco, Casa Municipal de Cultura Zacatecas, Jason Mena, Vanessa Rivero, Familia Tagle Patrone Rafael Penroz, ESAY Escuela de Artes de Yucatán.

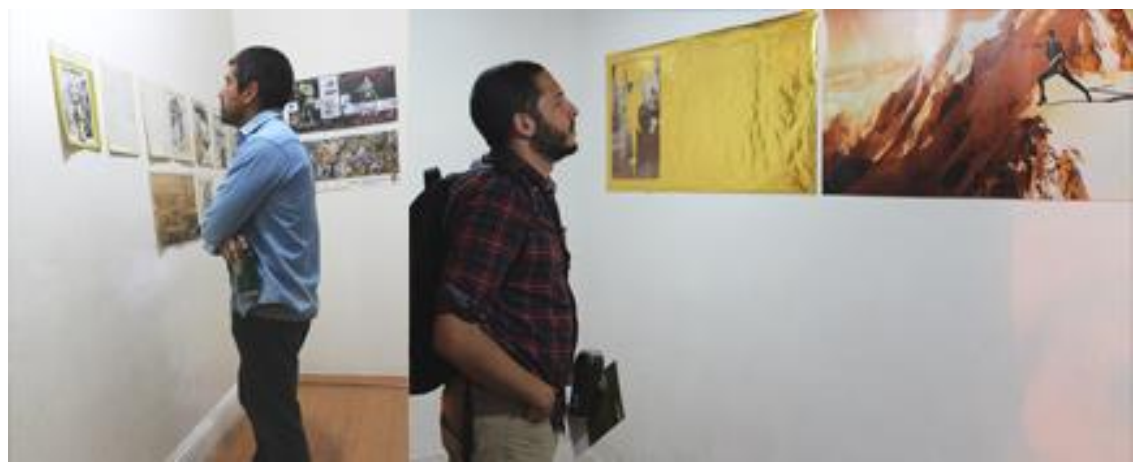

5 a 11. Registros Milica Ficción, Zacatecas, 2016; 12 y 13. Registro Mute en Ciudad de México, 2016. 